\title{
Ethnobotanical and Biochemical Study of Berberis lycium Royle Collected from Different Areas of Azad Jammu and Kashmir
}

\author{
Syeda Maria Fiaz Bukhari $\mathbb{D}^{\mathrm{D}},{ }^{1}$ Ghazanfar Ali $\mathbb{D}^{\mathrm{D}},{ }^{1}$ Syed Rizwan Abbas $\mathbb{D}^{\mathrm{D}},{ }^{2}$ Zeeshan Anjum (iD), \\ Nasim Ahmed $\left(\mathbb{D},{ }^{3}\right.$ Ammara Munir $(D),{ }^{4}$ Abdul Wali $(D),{ }^{5}$ Muhammad Ayub $\left(\mathbb{D},{ }^{6}\right.$ \\ Kafaitullah Khan $\mathbb{D}^{7}$ Ahmed Khames $\mathbb{D}^{8},{ }^{8}$ and Muneeb Muhamed Musthafa $\mathbb{D}^{9}$ \\ ${ }^{1}$ Department of Biotechnology, University of Azad Jammu Kashmir, Muzaffarabad, Pakistan \\ ${ }^{2}$ Department of Biological Sciences, Karakoram International University, Gilgit, Pakistan \\ ${ }^{3}$ Agricultural Biotechnology Division, National Institute for Biotechnology and Genetic Engineering College, \\ Pakistan Institute of Engineering and Applied Sciences, Faisalabad, Pakistan \\ ${ }^{4}$ Department of Biotechnology, Virtual University of Pakistan, Lahore, Pakistan \\ ${ }^{5}$ Faculty of Life Sciences \& Informatics, \\ Balochistan University of Information Technology, Engineering and Management Sciences, 87100 Quetta, Pakistan \\ ${ }^{6}$ Institute of Biochemistry, University of Balochistan, Quetta, Pakistan \\ ${ }^{7}$ Department of Microbiology, University of Balochistan, Quetta 87300, Pakistan \\ ${ }^{8}$ Department of Pharmaceutics and Industrial Pharmacy, College of Pharmacy, Taif University, P.O. Box 11099, \\ Taif 21944, Saudi Arabia \\ ${ }^{9}$ Department of Biosystems Technology, Faculty of Technology, South Eastern University of Sri Lanka, University Park, \\ Oluvil \#32360, Sri Lanka
}

Correspondence should be addressed to Ghazanfar Ali; ali.phd.qau@gmail.com

Received 3 April 2021; Revised 31 July 2021; Accepted 24 August 2021; Published 26 September 2021

Academic Editor: Riaz Ullah

Copyright (C) 2021 Syeda Maria Fiaz Bukhari et al. This is an open access article distributed under the Creative Commons Attribution License, which permits unrestricted use, distribution, and reproduction in any medium, provided the original work is properly cited.

\begin{abstract}
Berberis lycium Royle has a long history of medicinal uses to treat different diseases. It naturally grows on the mountains of Indian subcontinent. Its ethnobotanical and biochemical study from the state of Azad Jammu and Kashmir (AJ\&K) was not previously explored. So, the objective of the current study was to explore the ethnobotanical and biochemical properties of the B. lycium Royle population of AJ\&K. For this purpose, samples of B. lycium Royle were randomly collected from five districts of Azad Jammu and Kashmir, including thirty-five locations. Demographic features of informants such as plant part used, methods of preparation, modes of administration, conservation status, and ethnomedicinal uses were documented. It was used for treating different diseases such as diabetes, arthritis, joint pain, and stomach ulcer. This plant is very famous for providing medicinal roots, leaves, and fruits which are extensively used in many parts of the world. The biochemical analysis was conducted for total phenolic contents (TPC), chlorophyll contents, and antioxidant activity. The highest level of TPC found was $88.66 \pm 1.07 \mu \mathrm{g} / \mathrm{g}$ of gallic acid equivalent phenolic (GAE) from leaves collected from Patikka (Chanjhal), Muzaffarabad District, AJ\&K. The highest total chlorophyll contents $(3.75 \pm 0.53 \mu \mathrm{g} / \mathrm{ml})$ were found in samples collected from Sathrian, Neelum District. The highest antioxidant activity with lowest IC50 value $(33.26 \mu \mathrm{g} / \mathrm{ml})$ was obtained from the root of sample collected from Bakreyali, Muzaffarabad District, as compared with other districts. The concentration of berberine was found to be 4.76 percent in the root bark of $B$. lycium Royle, estimated by high-performance liquid chromatography (HPLC). In syrup composition, $0.95 \mathrm{mg} / 5 \mathrm{ml}$ of berberine was used. Hence, it is concluded that amongst the five districts, the plant parts (stem, fruits, and root) collected from Muzaffarabad District, $\mathrm{AJ} \& \mathrm{~K}$, showed the highest medicinal potential due to its unique climatic conditions.
\end{abstract}




\section{Introduction}

Medicinal plants have been utilized as folk medicines for centuries, and many communities still depend on these plants for acquiring their primary health care needs [1]. In some cultures, plants are used because of their hallucinogenic character. In many parts of the world, veterinary therapeutics also use active compounds from plants [2]. Aromatic plants have high medicinal value and have long history of use as an effective and cheap source of remedy for several health disorders [3]. An ethnobotanical study showed that people get food, fodder for animals, medicine, material for building houses, crafts, tools of agriculture, and many other products such as poisons, resins, fuel, and paints from large number of less familiar plant resources which are present in nature as today's need $[4,5]$. There are different techniques and protocols used to achieve ethnobotanical knowledge (qualitative or quantitative method) about specific plants and their uses as well as caste or race's feature or study of a region $[5,6]$. Berberis lycium Royle is a high value medicinal plant with known history in folklore medicine and traditionally used to treat different human diseases [7], such as diabetes mellitus, liver disorders, abdominal problems, skin diseases, oral ulcers, kidney, conjunctivitis, piles, leprosy, jaundice, rheumatism, and bone fractures [7-9]. It has antiglycation and antidiabetic potential and is also used to treat jaundice, bone fractures, ophthalmic disorders, fever, menorrhagia, internal wounds, intestinal colic, throat pain, diarrhea, piles, and rheumatism [10]. Thus, it has acceptance among traditional medical practitioners [8]. Furthermore, it has been used either as a food [11] or as medicine [12] because of the presence of berberine, chinabine, balauchistanamine, karakoramine, palmatine, jhelumine, gilgitine, punjabine, sindamine, ascorbic acid, maleic acid, and acetic acid [13]. Berberine is one of the most abundant alkaloid in plant $[14,15]$. Berberine shows significant phytotherapeutic benefits, such as antidiarrheal, antimicrobial, antitoxic, antiprotozoal, and antitrachoma activities $[10,16]$. According to different studies, berberine can be extracted from B. lycium roots, fruits, leaves, and stem and used for the treatment of diabetes [9]. The root bark and extract are used in treating throat pain, dysentery, internal wounds, and sun blindness [7]. The root bark water extract is used against scabies, pustules, diabetes, and bone fracture [17]. The watery extract from the root is also used in wounds, gonorrhea, curative piles, unhealthy ulcers, acute conjunctive, ophthalmia (swollen and sore eyes), and jaundice [7]. Fruits and leaves are used for the treatment of diabetes and other diseases in Pakistan [18]. The whole plant is used for curing diabetes and other human illnesses [19]. The plant growth and development are dependent upon reactive oxygen species (ROS) production and signaling as ROS play key role in plant phytohormonal networks [20], which are produced during the cellular respiration. Antioxidants scavenge these ROS and synthetic antioxidants could create toxic effects, so natural antioxidants are preferred. Compounds from plants having high antioxidant effects could be a choice to develop new medicines [21]. B. lycium Royle is native to the Himalayan region. Its roots are rich in alkaloids (berberine, etc.) and yellowish in color and have other phytochemicals [22]. It contains $\mathrm{Cu}, \mathrm{Mn}, \mathrm{Ca}, \mathrm{K}, \mathrm{P}$, vitamin $\mathrm{A}$, vitamin $\mathrm{C}$, and vitamin $\mathrm{E}$. Ca is helpful in strengthening bones and teeth [7]. $\mathrm{Zn}$ and $\mathrm{Cu}$ are part of dietary sources involved in redox and enzymatic reactions [8]. $\mathrm{K}$ and $\mathrm{Na}$ are involved in membrane functions. Fe is the central atom of hemoglobin which helps in electron and oxygen carrier [15]. It is also attributed to prevention of cancer and atherosclerosis. Vitamin C is a cofactor of enzymes [7]. Animal and human studies showed that optimal intake of minerals such as $\mathrm{Cu}, \mathrm{K}, \mathrm{Zn}, \mathrm{Mn}$, and $\mathrm{Ca}$ decreases risk factors, including those related to cardiovascular disorders [15, 23]. The purpose of the present study was to collect ethnobotanical knowledge about B. lycium Royle from major growing areas of Azad Jammu and Kashmir (AJ\&K) and also its total phenolic contents, chlorophyll contents, antioxidant activity, and HPLC analysis from different places and to find the best environment for its maximum medicinal potential.

\section{Materials and Methods}

The current research was carried out for ethnobotanical and biochemical study of B. lycium Royle from five districts of AJ\&K region, i.e., Muzaffarabad, Hattian, Bagh, Poonch, and Neelum, as shown (Figure 1). The selection of these five districts is due to their major contribution to the production of B. lycium Royle in the region. This study was conducted from May 2014 to July 2017 by the Department of Biotechnology, University of Azad Jammu and Kashmir (UAJ\&K). This region is located between $73-75^{\circ}$ East longitude and $33-35^{\circ}$ North latitude and covers an area of $13,297 \mathrm{~km}^{2}$. The altitude of the study area varies between $600 \mathrm{~m}$ and $6325 \mathrm{~m}$ and so is the varying climate of the area. The verbal consent was obtained from each informant before conducting the interview process. The ethnobotanical study was completed in four phases: (i) description/selection of study area/locations, (ii) ethnomedicinal field survey (primary data), (iii) sample collection and their biochemical analysis (total phenolic compounds, chlorophyll contents, and antioxidant activity), and (iv) statistical analysis (secondary data) and data compilation/documentation.

2.1. Field Survey and Data Collection. The study area was consistently visited from May 2014 to July 2017. The prime spots were selected from AJ\&K region, i.e., Muzaffarabad, Hattian, Bagh, Poonch, and Neelum. Fieldwork was implemented for the conservation status of plant and plant diversity. The field work included observations, interviews, and guided field walks. During fieldwork, two methods were frequently used. The field survey aimed to gather field data and activities, such as (i) plant collection, (ii) local knowledge regarding medicinal plant, (iii) identifying related significance to plants, (iv) conservation requisites, (v) medicinal uses, (vi) mode of preparation, and (vii) diseases treated through well-planned questionnaires, interviews, and keen observations. The questionnaire and interview method helped to document indigenous folk knowledge by involving knowledgeable persons (hakims, farmers, 


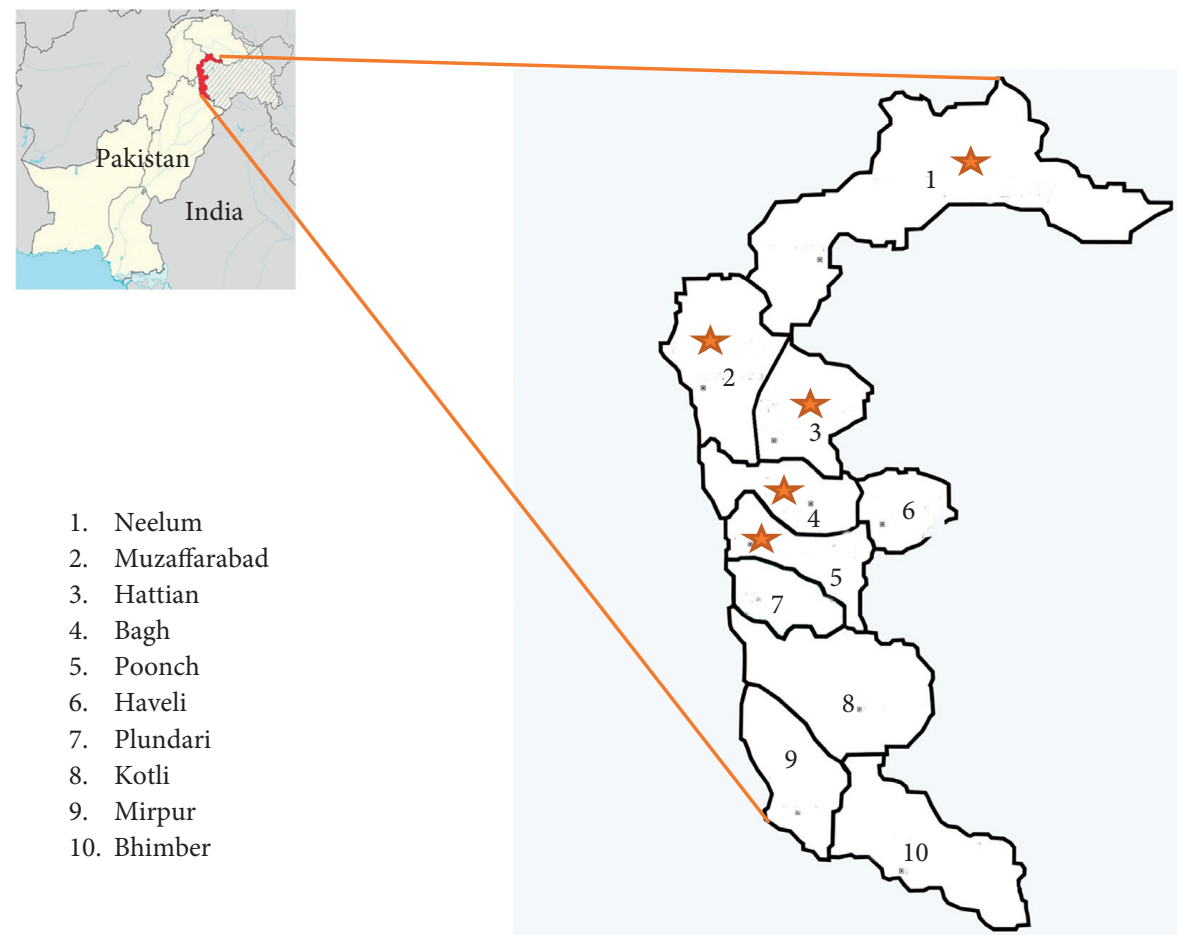

Figure 1: District-wise map of Azad Jammu and Kashmir; the districts from which samples were collected in the current study are labeled with red-colored star.

herdsmen, etc.) The plants were collected, and their traditional uses were asked from individuals. The plant's use which is just mentioned by one or two people is also important, but their reliability ratio is lesser, and it indicates that traditional knowledge of area about plants is disappearing from the area [2]. An ethnobotanist may use qualitative or quantitative method depending on the purpose of study [24]. The ethnobotanical data were tested and matched with the existing literature and were analyzed both qualitatively and quantitatively. During fieldwork, interviews were conducted with local inhabitants. In the interview system, a questionnaire method was used to take interviews from houses, markets, or fields. The use of local languages was preferred for collecting data because it is very essential to know the real facts about local flora [25] and local peoples. During this process, local methods of collection, drying, storage, harvesting, utilization, and processing of Berberis lycium Royle were practiced and noted. The plants' flowering/fruiting seasons were noted, and flowers/fruits were pressed and preserved at the same time during the ethnobotanical study of plant. All the samples were recorded in three replicates. One-way ANOVA $(P<0.05)$ was performed for statistical analysis of the data.

2.2. Identification of Plant. The collected plant species was identified by Dr. Tariq, Department of Botany, University of Azad Jammu \& Kashmir. The accession number of plants is AKASH 000601, and voucher number is SMF-01. Biochemical analysis was also conducted on these samples collected from five districts of AJ\&K (Figure 1). The biochemical analysis was carried out on the samples of B. lycium
Royle for the estimation of phenolic contents, chlorophyll contents, and antioxidant activity.

2.3. Estimation of Total Phenolic Contents (TPC). The total phenolic contents were determined by adding $0.5 \mathrm{~mL}$ of the plant extract to $2.5 \mathrm{~mL}$ of Folin-Ciocâlteu's phenol reagent $(10 \% v / v)$ and $2 \mathrm{~mL}$ of $\mathrm{NaHCO} 3(7.5 \% w / v$ in water). The reaction mixture was incubated at $45^{\circ} \mathrm{C}$ for $40 \mathrm{~min}$, and the absorbance was measured at $765 \mathrm{~nm}$ using a spectrophotometer. Distilled water was used as a standard phenol [26]. Different concentrations of gallic acid were measured to find the linear regression using the following equation:

$$
y=0.0012 x+0.0396 R^{2}=0.9991
$$

2.4. Estimation of Chlorophyll. The leaf samples $\left(1 \mathrm{~cm}^{2}\right)$ of each ecotype were taken with $5 \mathrm{ml}$ ethanol in a test tube. The test tubes with samples were kept overnight to extract the chlorophyll contents. The chlorophyll extraction was measured spectrophotometrically at $646.6 \mathrm{~nm}$ and $663.6 \mathrm{~nm}$. The values were calculated using the formula [27].

2.5. Antioxidant Activity by 2,2-Diphenyl-1-picrylhydrazyl (DPPH) Radical Scavenging. The antioxidant activities of the plant extract were measured by using the stable DPPH radical according to the method of [11]. $0.25 \mathrm{mM}$ solution of DPPH radical $(0.5 \mathrm{ml})$ was added to the sample solution in ethanol $(1 \mathrm{ml})$ at different concentrations of aqueous extract of B. lycium Royle. The mixture was shaken vigorously and left to stand for 30 minutes in the dark, and the absorbance 
was measured at $517 \mathrm{~nm}$. The capacity to scavenge the DPPH radical was calculated using the following equation: percentage scavenging $=[(A o-A s) / A o)]^{*} 100$, where $A o$ is the absorbance of the control reaction and $A s$ is the absorbance of the sample itself. IC50 was calculated after plotting data and getting the linearity correlation equation.

2.6. Preparation of Syrup Formation. The root bark of B. lycium Royle was selected from Muzaffarabad District (Patkai) The sample was washed thoroughly to remove dirt and stain. The sample was placed in the shade for almost 20 days in order to get dry. After drying, the sample was grounded into powder form. An aqueous solution was made of the powder form. The patent was filed, Abbas Nutraceutical Product made from locally available medicinal plant B. lycium Royle.

2.7. HPLC Analysis of Alkaloids. The quantification of berberine from the root extract of $B$. lycium was carried out by using HPLC, Cat \# PM 951505-0, column C-18 isocratic, $5 \mu \mathrm{m}, 4.6 \mathrm{~mm} \times 250 \mathrm{~mm}$. The liquid chromatography used was DLC-20 by Star-Chrom Lite. The software used was also Star-Chrom. The single-beam UV-spectrophotometer by IRMECO Germany, Model ${ }^{*} 2020$, was used for spectrum analysis and absorbance peak comparison. The mobile phase contains $50 \mathrm{mM}$ potassium dehydrogenase phosphate and acetonitrile in $70: 30$, and $\mathrm{pH}$ of solution was adjusted to 3 with phosphoric acid. The flow rate was retained $1 \mathrm{ml} / \mathrm{min}$, and the injection volume was $20 \mu \mathrm{l}$. The berberine quantification was done at $271 \mathrm{~nm}$. The peak in the B. lycium Royle sample was observed by retention time. The analysis was conducted in triplicate, and berberine was found. The validated method for HPLC is given in [28].

2.8. Statistical Analysis. The data in this study were expressed as a mean of triplicate. Statistical comparison and one-way ANOVA followed by Dunnett's multiple comparisons test were made in Prism, version 6.00, GraphPad software for Windows, La Jolla, California, USA, http://www.graphpad.com.

\section{Results and Discussions}

There are 10 districts in Azad Jammu and Kashmir. Data were collected from five districts of AJ\&K, i.e., Muzaffarabad, Hattian, Bagh, Poonch, and Neelum, as shown (Table 1). These five districts were selected because they cover the major area of B. lycium Royle in the state of AJ\&K.

3.1. Ethnobotanical Study. In the current study, there were 35 informants (17 males and 18 females) having age ranging from 22 to 75 years. Among them, 11 were housewives, 10 were teachers, 9 were shopkeepers, 3 were farmers, and 2 were lecturers. The information (local name, mode of preparation, and medicinal uses) was collected through questionnaire, interviews, and discussions with villagers. Our questionnaire allowed descriptive response on plant prescribed, plant part used, and detailed information on the mode of preparation (paste, powder, and juice). Root bark powder was used for treating different diseases in the form of paste, given orally or placed on a wound or cut directly (Table 2). Ethnobotany is perhaps the most important method to study natural resources and their interaction by indigenous peoples. Traditional knowledge of these resources, orally transferred from generation to generation, allowed us to work with local people to explore the importance of plant [29]. This study provided information about some therapeutic uses of B. lycium Royle. It was found that medicinal values of $B$. lycium Royle are difficult to maintain because of their potential uses; therefore, they are recommended for viable harvest, not being used as fire wood [30]. People use plants in various ways such as medicine, timber wood, fuel wood, food, and fodder [31].

3.2. TPC Estimation. TP contents' amount was estimated by using Folin-Ciocâlteu's phenol reagent and is denoted in GAE (Table 3). The highest phenolic contents of roots were observed in Medan Syedan $(53.85 \pm 1.11 \mu \mathrm{g} / \mathrm{g})$ and the lowest in Qadrabad $(9.50 \pm 0.95 \mu \mathrm{g} / \mathrm{g})$. The phenolic contents of stem showed the highest value of $56.39 \mu \mathrm{g} / \mathrm{g} \pm 2.01$ in Medan Syedan and the lowest value of $8.18 \pm 0.72 \mu \mathrm{g} / \mathrm{g}$. The phenolic contents of leaves were the highest in Patikka (Chanjhal) $(88.66 \pm 1.07 \mu \mathrm{g} / \mathrm{g})$ and the lowest in Dhaman Jholi $(8.24 \pm 1.25 \mu \mathrm{g} / \mathrm{g})$. The thorn showed the highest concentration of $61.22 \pm 1.4 \mu \mathrm{g} / \mathrm{g}$ in Patikka (Chanjhal), and $11.14 \pm 1.7 \mu \mathrm{g} / \mathrm{g}$ was the value for Dhaman Jholi. Patikka (Chanjhal) again showed the highest value of phenolic contents in fruits of $66.43 \pm 1.09 \mu \mathrm{g} / \mathrm{g}$, and Dhaman Jholi was the lowest with $10.36 \pm 1.47 \mu \mathrm{g} / \mathrm{g}$. TP contents varied among the plant samples collected from different locations. The variation of phenolic contents was due to environment, soil texture, and altitude differences. It could be said that phenolic content variations were the result of a plant's interaction to its environment. The change in phenols directly affects the medicinal quality of the plant [32]. The main cause for the variation in phenolic contents was due to difference in soil texture, environment, and altitude. Stem, leaf, and inflorescent characters were classified for the identification of Berberis species [33].

3.3. Estimation of Chlorophyll. Chlorophyll concentrations were calculated in different demographic regions. The values of chlorophyll $\mathrm{a}$ and chlorophyll $\mathrm{b}$ and the total amount of chlorophyll were expressed as $\mu \mathrm{g} / \mathrm{ml}$ (Table 4 ). The chlorophyll a content was highest $(2.16 \pm 0.13 \mu \mathrm{g} / \mathrm{ml})$ in Bagh and lowest $(0.24 \pm 0.06 \mu \mathrm{g} / \mathrm{ml})$ in Shahkot. The chlorophyll b was highest in Sathrian $(2.66 \mu \mathrm{g} / \mathrm{ml} \pm 0.41)$ and lowest in Rawalakot $(0.15 \pm 0.04 \mu \mathrm{g} / \mathrm{ml})$. The total chlorophyll content was found highest in Sathrian $(3.75 \pm 0.53 \mu \mathrm{g} / \mathrm{ml})$ and lowest in Sheesha Mali $(0.53 \pm 0.15 \mu \mathrm{g} / \mathrm{ml})$. The chlorophyll content changed in different areas as well as within the same plant due to differences in leaves' reception of sunlight. It also varied in different areas due to shade and time of exposure to sunlight [20]. 
TABLE 1: Information of five districts of AJ\&K from where B. lycium Royle samples were collected.

\begin{tabular}{lccccc}
\hline District & Altitude $($ feet $)$ & Latitude $\left({ }^{\circ} \mathrm{N}\right)$ & Longitude $\left({ }^{\circ} \mathrm{E}\right)$ & Flowering season & Fruit ripening season \\
\hline Muzaffarabad & 58147 & 34.38362 & 73.471054 & April-May & June-August \\
Hattian & 5362.167 & 34.26704 & 73.7432 & April-May & June-August \\
Bagh & 2107.5 & 33.9441151 & 73.7918 & April-June & July-October \\
Poonch & 5051.5 & 33.8423496 & 73.7507 & June-July & August-October \\
Neelum & 14989.5 & 34.49522 & 73.9106 & April-May & July-August \\
\hline
\end{tabular}

Local name of the plant is "sunbal."

TABLE 2: The number of informants who have used B. lycium Royle to treat different diseases.

\begin{tabular}{lcc}
\hline S. no. & Root bark powder used for treating different diseases & No. of informants \\
\hline 1 & Joint pain & 3 \\
2 & Diarrhea and joint pain & 2 \\
3 & Diabetes and joint pain & 2 \\
4 & Diabetes & 4 \\
5 & Broken bone and arthritis & 6 \\
6 & Broken bones & 16 \\
7 & Arthritis & 2 \\
& Grand total & 35 \\
\hline
\end{tabular}

Table 3: Total phenolic contents estimated in root, stem, leaves, thorn, and fruits of Berberis lycium Royle.

\begin{tabular}{|c|c|c|c|c|c|}
\hline \multirow{2}{*}{ Source/location } & \multicolumn{5}{|c|}{ Total phenolic contents } \\
\hline & $\operatorname{Root}(\mu \mathrm{g} / \mathrm{g} \pm \mathrm{SD})$ & Stem $(\mu \mathrm{g} / \mathrm{g} \pm \mathrm{SD})$ & Leaves $(\mu \mathrm{g} / \mathrm{g} \pm \mathrm{SD})$ & Thorn $(\mu \mathrm{g} / \mathrm{g} \pm \mathrm{SD})$ & Fruit $(\mu \mathrm{g} / \mathrm{g} \pm \mathrm{SD})$ \\
\hline Serli Scha & $16.77 \pm 0.89$ & $14.60 \pm 0.72$ & $35.74 \pm 1.10$ & $23.90 \pm 1.89$ & $25.46 \pm 0.77$ \\
\hline Copra Gali & $18.50 \pm 0.66$ & $23.45 \pm 0.92$ & $17.69 \pm 0.87$ & $21.53 \pm 2.04$ & $18.67 \pm 0.67$ \\
\hline Sadbun & $9.56 \pm 1.02$ & $10.45 \pm 0.58$ & $13.56 \pm 1.27$ & $12.57 \pm 1.90$ & $11.52 \pm 1.11$ \\
\hline Patikka (Chanjhal) & $50.16 \pm 1.78$ & $42.75 \pm 0.90$ & $88.66 \pm 1.07$ & $61.22 \pm 1.45$ & $66.43 \pm 1.09$ \\
\hline Bakreyali & $12.08 \pm 1.65$ & $43.27 \pm 0.71$ & $38.71 \pm 0.79$ & $34.02 \pm 2.57$ & $28.66 \pm 1.47$ \\
\hline Ranjhata & $15.80 \pm 1.11$ & $22.44 \pm 0.92$ & $33.47 \pm 1.31$ & $24.10 \pm 1.10$ & $24.75 \pm 0.47$ \\
\hline Garhi Dupatta & $12.33 \pm 1.57$ & $8.18 \pm 0.72$ & $12.11 \pm 1.82$ & $12.49 \pm 2.30$ & $12.05 \pm 1.58$ \\
\hline Dhaman Jholi & $12.40 \pm 1.78$ & $10.19 \pm 0.70$ & $8.24 \pm 1.25$ & $11.14 \pm 1.73$ & $10.36 \pm 1.47$ \\
\hline Bagh & $12.18 \pm 1.88$ & $10.45 \pm 0.87$ & $14.35 \pm 2.22$ & $12.12 \pm 1.02$ & $12.55 \pm 1.36$ \\
\hline Arja & $45.77 \pm 1.17$ & $14.27 \pm 1.00$ & $31.80 \pm 2.81$ & $30.97 \pm 1.49$ & $35.71 \pm 1.28$ \\
\hline Qadrabad & $9.50 \pm 0.95$ & $44.72 \pm 1.11$ & $12.23 \pm 1.62$ & $22.91 \pm 1.59$ & $14.67 \pm 1.26$ \\
\hline Rawalakot & $18.62 \pm 1.44$ & $33.69 \pm 1.31$ & $31.20 \pm 1.64$ & $28.05 \pm 1.41$ & $25.40 \pm 0.94$ \\
\hline Khrick & $27.12 \pm 1.50$ & $33.39 \pm 0.90$ & $19.55 \pm 1.08$ & $27.00 \pm 1.51$ & $24.54 \pm 1.34$ \\
\hline Bhanjhosa & $15.85 \pm 1.15$ & $23.37 \pm 1.18$ & $34.38 \pm 2.00$ & $24.17 \pm 1.18$ & $24.34 \pm 0.97$ \\
\hline Haryala & $13.59 \pm 1.31$ & $11.56 \pm 1.02$ & $11.75 \pm 2.23$ & $12.71 \pm 1.90$ & $12.40 \pm 1.57$ \\
\hline Subai Mali & $37.88 \pm 1.05$ & $24.38 \pm 1.01$ & $10.41 \pm 2.12$ & $25.04 \pm 1.44$ & $24.21 \pm 1.18$ \\
\hline Sheesha Mali & $15.80 \pm 0.92$ & $14.53 \pm 1.26$ & $10.80 \pm 1.95$ & $13.25 \pm 1.05$ & $12.81 \pm 0.95$ \\
\hline Kalis & $12.52 \pm 1.37$ & $11.25 \pm 0.81$ & $11.49 \pm 3.01$ & $11.45 \pm 1.75$ & $10.58 \pm 1.10$ \\
\hline Sarran Chatiyan & $10.59 \pm 1.01$ & $10.53 \pm 1.02$ & $12.71 \pm 1.94$ & $12.14 \pm 2.77$ & $11.32 \pm 1.27$ \\
\hline Gori Syedan & $13.19 \pm 0.93$ & $13.28 \pm 1.18$ & $12.09 \pm 1.36$ & $14.01 \pm 2.34$ & $11.95 \pm 0.50$ \\
\hline Neelum & $9.53 \pm 1.38$ & $22.42 \pm 1.99$ & $34.40 \pm 0.83$ & $23.67 \pm 2.68$ & $22.42 \pm 1.57$ \\
\hline Ziarat & $14.26 \pm 0.73$ & $19.43 \pm 1.29$ & $12.82 \pm 0.79$ & $16.05 \pm 1.43$ & $14.66 \pm 1.24$ \\
\hline Thanger & $14.88 \pm 1.17$ & $19.36 \pm 1.50$ & $17.47 \pm 0.65$ & $17.27 \pm 1.13$ & $16.26 \pm 0.69$ \\
\hline Chinar Pura & $12.67 \pm 0.81$ & $13.49 \pm 1.19$ & $11.68 \pm 1.98$ & $12.86 \pm 1.58$ & $11.67 \pm 1.16$ \\
\hline Shahkot & $13.46 \pm 1.16$ & $14.04 \pm 1.69$ & $10.99 \pm 1.48$ & $12.89 \pm 1.54$ & $12.16 \pm 1.17$ \\
\hline Bagna & $16.65 \pm 1.48$ & $15.13 \pm 1.24$ & $14.30 \pm 0.98$ & $15.83 \pm 1.64$ & $14.57 \pm 0.62$ \\
\hline Medan Syedan & $53.85 \pm 1.11$ & $56.39 \pm 2.01$ & $13.24 \pm 1.08$ & $41.33 \pm 0.96$ & $35.68 \pm 0.95$ \\
\hline Lawat & $18.77 \pm 1.21$ & $16.24 \pm 1.61$ & $17.41 \pm 0.82$ & $17.56 \pm 0.78$ & $17.73 \pm 1.05$ \\
\hline Kundal Shahi & $13.56 \pm 1.42$ & $13.72 \pm 1.92$ & $31.47 \pm 0.65$ & $19.40 \pm 1.08$ & $21.87 \pm 1.46$ \\
\hline Sathrian & $34.89 \pm 1.13$ & $27.75 \pm 1.89$ & $46.95 \pm 1.54$ & $36.83 \pm 1.08$ & $40.12 \pm 1.81$ \\
\hline Laala & $15.40 \pm 0.64$ & $13.92 \pm 1.60$ & $11.23 \pm 2.47$ & $13.92 \pm 1.61$ & $12.63 \pm 0.74$ \\
\hline Palang & $18.23 \pm 0.71$ & $15.10 \pm 1.37$ & $13.09 \pm 1.31$ & $15.38 \pm 0.96$ & $15.46 \pm 0.79$ \\
\hline Keran & $16.47 \pm 1.08$ & $12.23 \pm 1.87$ & $12.53 \pm 2.23$ & $13.50 \pm 1.77$ & $13.34 \pm 1.01$ \\
\hline Ethai & $13.29 \pm 0.83$ & $12.74 \pm 2.18$ & $13.11 \pm 1.26$ & $13.53 \pm 2.05$ & $13.15 \pm 1.22$ \\
\hline Slam Pura & $22.19 \pm 1.26$ & $13.28 \pm 1.43$ & $9.13 \pm 1.19$ & $14.54 \pm 1.11$ & $15.97 \pm 1.76$ \\
\hline
\end{tabular}

The $P$ value was $<0.0001$, and the CI was 99 percent. 
TABLE 4: Chlorophyll a, chlorophyll b, and total chlorophyll in B. lycium Royle of different places having a variety of chlorophyll contents due to differences in the environment of places.

\begin{tabular}{|c|c|c|c|}
\hline Location of the samples & Chlorophyll a $(\mu \mathrm{g} / \mathrm{ml} \pm \mathrm{SD})$ & Chlorophyll b $(\mu \mathrm{g} / \mathrm{ml} \pm \mathrm{SD})$ & Total chlorophyll $(\mu \mathrm{g} / \mathrm{ml} \pm \mathrm{SD})$ \\
\hline Serli Scha & $1.52 \pm 0.35$ & $0.27 \pm 0.07$ & $1.79 \pm 0.41$ \\
\hline Copra Gali & $1.69 \pm 0.09$ & $0.31 \pm 0.07$ & $2.01 \pm 0.05$ \\
\hline Sadbun & $1.21 \pm 0.20$ & $1.03 \pm 0.09$ & $2.24 \pm 0.28$ \\
\hline Patikka (Chanjhal) & $0.96 \pm 0.16$ & $1.31 \pm 0.20$ & $2.27 \pm 0.18$ \\
\hline Bakreyali & $1.12 \pm 0.06$ & $1.11 \pm 0.16$ & $2.23 \pm 0.16$ \\
\hline Garhi Dupatta & $0.33 \pm 0.10$ & $1.32 \pm 0.26$ & $1.65 \pm 0.17$ \\
\hline Dhaman Jholi & $1.29 \pm 0.23$ & $2.42 \pm 0.18$ & $3.71 \pm 0.15$ \\
\hline Bagh & $2.16 \pm 0.13$ & $1.41 \pm 0.04$ & $3.57 \pm 0.09$ \\
\hline Arja & $1.41 \pm 0.14$ & $0.23 \pm 0.05$ & $1.65 \pm 0.09$ \\
\hline Qadrabad & $0.53 \pm 0.07$ & $0.69 \pm 0.07$ & $1.23 \pm 0.14$ \\
\hline Rawalakot & $1.47 \pm 0.13$ & $0.15 \pm 0.04$ & $1.62 \pm 0.12$ \\
\hline Khrick & $1.49 \pm 0.20$ & $0.24 \pm 0.04$ & $1.73 \pm 0.20$ \\
\hline Bhanjhosa & $1.52 \pm 0.17$ & $0.40 \pm 0.02$ & $1.92 \pm 0.15$ \\
\hline Haryala & $0.28 \pm 0.06$ & $0.70 \pm 0.11$ & $0.98 \pm 0.16$ \\
\hline Subai Mali & $0.49 \pm 0.09$ & $2.45 \pm 0.08$ & $2.94 \pm 0.14$ \\
\hline Sheesha Mali & $0.26 \pm 0.02$ & $0.30 \pm 0.14$ & $0.56 \pm 0.15$ \\
\hline Kalis & $0.64 \pm 0.15$ & $0.71 \pm 0.09$ & $1.35 \pm 0.21$ \\
\hline Sarran Chatiyan & $0.53 \pm 0.18$ & $1.42 \pm 0.27$ & $1.95 \pm 0.12$ \\
\hline Gori Syedan & $1.51 \pm 0.14$ & $0.66 \pm 0.15$ & $2.17 \pm 0.06$ \\
\hline Neelum & $0.92 \pm 0.09$ & $0.79 \pm 0.19$ & $1.71 \pm 0.20$ \\
\hline Ziarat & $1.90 \pm 0.07$ & $0.77 \pm 0.10$ & $2.67 \pm 0.03$ \\
\hline Thanger & $1.72 \pm 0.22$ & $0.37 \pm 0.12$ & $2.09 \pm 0.31$ \\
\hline Chinar Pura & $0.97 \pm 0.06$ & $1.21 \pm 0.23$ & $2.18 \pm 0.18$ \\
\hline Shahkot & $0.24 \pm 0.06$ & $0.41 \pm 0.05$ & $0.65 \pm 0.07$ \\
\hline Bagna & $0.67 \pm 0.09$ & $1.72 \pm 0.28$ & $2.39 \pm 0.36$ \\
\hline Medan Syedan & $0.94 \pm 0.16$ & $0.84 \pm 0.01$ & $1.78 \pm 0.17$ \\
\hline Lawat & $0.55 \pm 0.08$ & $1.72 \pm 0.27$ & $2.26 \pm 0.28$ \\
\hline Kundal Shahi & $0.66 \pm 0.14$ & $1.16 \pm 0.11$ & $1.82 \pm 0.11$ \\
\hline Sathrian & $1.10 \pm 0.12$ & $2.66 \pm 0.41$ & $3.75 \pm 0.53$ \\
\hline Laala & $0.60 \pm 0.19$ & $1.39 \pm 0.40$ & $1.99 \pm 0.60$ \\
\hline Palang & $1.41 \pm 0.19$ & $0.17 \pm 0.07$ & $1.57 \pm 0.13$ \\
\hline Keran & $0.26 \pm 0.14$ & $1.48 \pm 0.16$ & $1.74 \pm 0.07$ \\
\hline Ethai & $1.35 \pm 0.33$ & $1.38 \pm 0.45$ & $2.73 \pm 0.34$ \\
\hline Slam Pura & $1.60 \pm 0.17$ & $1.65 \pm 0.20$ & $3.24 \pm 0.31$ \\
\hline
\end{tabular}

$P$ value $<0.0001$ and $\mathrm{CI}=99 \%$.

3.4. DPPH Radical Scavenging Assay. The DPPH method is used for the radical scavenging activity of antioxidants. DPPH is a stable organic free radical and presents the ability to accept hydrogen radical or an electron. Scavenging activity was calculated in percentage of inhibition (Table 5). The IC50 for stem showed the highest value of $810.51 \mu \mathrm{g} / \mathrm{ml}$ in Serli Scha and the lowest for Kaalis $(36.63 \mu \mathrm{g} / \mathrm{ml})$. The IC50 for root showed the highest value of 513.33 in Serli Scha and the lowest for Bakreyali $(33.26 \mu \mathrm{g} / \mathrm{ml})$. The IC50 for leaves showed the highest value of $481.23 \mu \mathrm{g} / \mathrm{ml}$ in Sarran Chatiyan and the lowest for Subhai Mali $(40.82 \mu \mathrm{g} / \mathrm{ml})$. Bakreyali showed $33.26 \mu \mathrm{g} / \mathrm{ml}$. The IC50 for thorn showed the highest value of $474.14 \mu \mathrm{g} / \mathrm{ml}$ for Laala and the lowest for Bagna $(8.69 \mu \mathrm{g} / \mathrm{ml})$. The highest antioxidant activity was exhibited by the thorn of plants collected from Bagna, having the lowest IC50 of $8.69 \mu \mathrm{g} / \mathrm{ml}$. Stem and fruits showed the highest antioxidant activity compared with other parts, while roots also exhibited good antioxidant potential. The root bark of $B$. lycium is the best antioxidant compared to ascorbic acid and many other plants [20]. Antioxidant activity among the different parts of the plant and among different plants varies depending on the function and mechanism of phenolic compounds [34]. The antioxidant activity is also due to alkaloids present in its different parts, and that may be a reason that phenolic contents and antioxidant activity are not related very much in the present study [35].

3.5. Extraction of Alkaloids from the Root Bark. Berberine is a major alkaloid that is found in B. lycium Royle, having a concentration of $4.1 \%$ in the root bark of the plant [15]. Berberine shows significant phytotherapeutic benefits $[10,16]$. Berberine can be extracted from B. lycium Royle roots, fruits, leaves, and stem [9]. Berberine is a major alkaloid present in Berberis species and is said to be a very active compound with various pharmacological properties [36]. Berberine is considered as the most important alkaloid, mainly used by the inhabitants to solve health problems [20]. There are two types of alkaloids, namely, palmatine and berberine, extracted from roots of this medicinal plant [37].

3.6. Concentration of Berberine. Berberine is a major alkaloid found in our product B. lycium Royle, having a concentration of 4.76 percent in root bark as estimated by HPLC (Figure 2). 
TABLe 5: IC50 concentrations in B. lycium Royle.

\begin{tabular}{|c|c|c|c|c|c|}
\hline \multirow{2}{*}{ Source } & \multicolumn{5}{|c|}{ DPPH IC50 of B. lycium Royle } \\
\hline & Root & Stem & Leaves & Thorn & Fruit \\
\hline Serli Scha & 513.33 & 810.52 & 150.89 & 43.94 & 662.24 \\
\hline Copra Gali & 103.97 & 586.16 & 132.24 & 343.16 & 382.51 \\
\hline Sadbun & 501.38 & 154.19 & 168.48 & 163.24 & 463.95 \\
\hline Patikka (Chanjhal) & 122.72 & 39.54 & 382.72 & 70.21 & 340.50 \\
\hline Bakreyali & 33.26 & 211.98 & 123.32 & 215.08 & 409.37 \\
\hline Ranjhata & 190.54 & 157.67 & 150.80 & 355.34 & 154.84 \\
\hline Garhi Dupatta & 244.44 & 469.71 & 457.84 & 444.47 & 411.55 \\
\hline Dhaman Jholi & 218.57 & 231.64 & 136.00 & 76.25 & 217.98 \\
\hline Bagh & 176.59 & 397.57 & 391.96 & 443.50 & 162.13 \\
\hline Arja & 219.24 & 471.85 & 40.83 & 167.38 & 169.37 \\
\hline Qadrabad & 466.86 & 406.33 & 236.74 & 183.62 & 202.42 \\
\hline Rawalakot & 401.07 & 36.64 & 207.59 & 280.19 & 368.04 \\
\hline Khrick & 206.74 & 178.47 & 481.23 & 455.59 & 435.09 \\
\hline Bhanjhosa & 149.25 & 472.25 & 153.68 & 47.44 & 368.04 \\
\hline Haryala & 375.42 & 376.13 & 433.84 & 239.11 & 461.68 \\
\hline Subai Mali & 406.80 & 335.92 & 200.92 & 154.16 & 418.66 \\
\hline Sheesha Mali & 183.62 & 215.41 & 330.19 & 177.40 & 398.18 \\
\hline Kalis & 141.83 & 390.21 & 448.05 & 418.28 & 273.43 \\
\hline Sarran Chatiyan & 163.17 & 417.94 & 170.57 & 440.38 & 119.02 \\
\hline Gori Syedan & 384.60 & 141.73 & 399.00 & 203.39 & 468.88 \\
\hline Neelum & 221.07 & 457.58 & 194.63 & 74.48 & 469.26 \\
\hline Ziarat & 152.34 & 447.73 & 182.89 & 46.07 & 177.60 \\
\hline Thanger & 256.81 & 199.24 & 219.52 & 270.24 & 234.79 \\
\hline Chinar Pura & 113.04 & 225.69 & 458.56 & 202.94 & 73.16 \\
\hline Shahkot & 253.37 & 128.21 & 372.11 & 87.46 & 374.93 \\
\hline Bagna & 411.86 & 477.51 & 362.20 & 8.70 & 360.01 \\
\hline Medan Syedan & 252.29 & 130.99 & 243.34 & 342.59 & 438.27 \\
\hline Lawat & 167.40 & 307.55 & 173.40 & 203.19 & 31.01 \\
\hline Kundal Shahi & 382.77 & 423.19 & 295.02 & 456.71 & 74.40 \\
\hline Sathrian & 138.77 & 333.25 & 191.60 & 226.68 & 371.96 \\
\hline Laala & 143.82 & 315.15 & 437.53 & 474.15 & 468.42 \\
\hline Palang & 47.06 & 392.23 & 261.11 & 196.18 & 147.96 \\
\hline Keran & 378.59 & 39.18 & 202.14 & 245.97 & 226.53 \\
\hline Ethai & 103.08 & 423.16 & 211.22 & 257.16 & 163.53 \\
\hline Slam Pura & 513.33 & 810.52 & 150.89 & 43.94 & 662.24 \\
\hline
\end{tabular}

IC50 is the concentration at which $50 \%$ scavenging activity is inhibited.

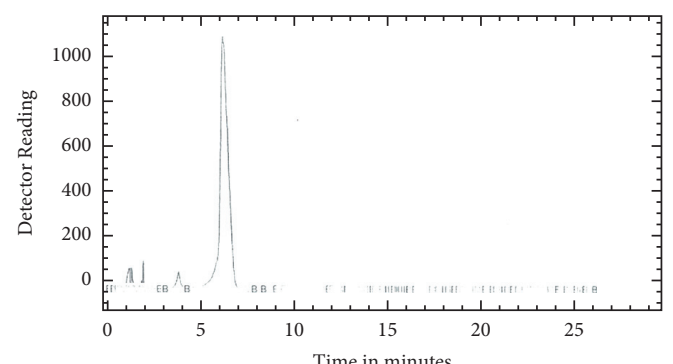

PEAK REPORT

\# begin end area

$1 \quad 4.86-7.32 \quad 33845$ percent maximum time begins name

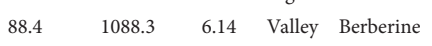

(a)

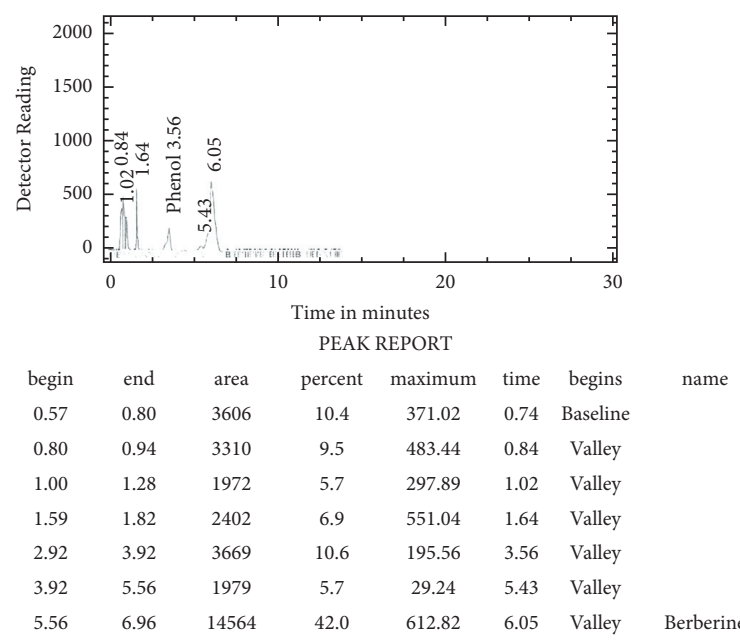

(b)

Figure 2: The retention peak of HPLC in berberine reference (a). The retention peak of B. lycium Royle sample collected from Patikka, Muzaffarabad, AJ\&K (b). 
3.7. Syrup Formation and Chemical Composition. Syrup formation was done by adding these constituents, i.e., the root bark extract of B. lycium Royle, sorbitol, methylene paraben, propyl paraben, propylene glycerol, dextrose, and flavour. Chemical composition of syrup per serving (1 table spoon): vitamin A (56.75 microgram), vitamin C (1.94 mg), calcium (3.24 mg), sodium (1.68 mg), phosphorous $(2.73 \mathrm{mg})$, potassium $(13.1 \mathrm{mg})$, iron $(0.17 \mathrm{mg})$, zinc $(1.88 \mathrm{mg}), \mathrm{Mn}(0.0055 \mathrm{mg})$, and berberine $(0.95 \mathrm{mg})$. Fruits and thorns may be used for the development of antioxidant compounds or combinations. Fruits could also be used in its raw form [16]. A wide variety of minerals are also documented in B. lycium Royle such as $\mathrm{Na}, \mathrm{Cu}, \mathrm{Ca}, \mathrm{S}, \mathrm{Fe}, \mathrm{Zn}, \mathrm{Mn}$, and $\mathrm{Pb}$ that is enough to prepare syrup $[15,16]$. Nowadays, nutraceuticals become popular among scientists and are made from medicinal plants [37].

\section{Conclusion}

Berberis lycium Royle is under heavy pressure from human activities including overexploitation, overgrazing, deforestation, and unscientific ways of collection. An increase in human population leads to depletion of natural resources. Because of the low potential of natural regeneration, constant high use is posing a great risk to B. lycium Royle. Increased livestock is also destroying this plant as they graze its leaves and branches due to its good taste. Goats specifically like to feed on this plant. The increasing human population is destroying the habitat of the plant. Habitat degradation is also due to deforestation, overexploitation, livestock grazing, and unscientific ways of collection. Other factors contributing to this problem are fuel wood cutting, stall feeding, soil erosion, fires, lack of awareness, weak law enforcement, and smuggling. As root bark of B. lycium Royle is used for the treatment, local Hakeems are using every possible way to obtain roots, resulting damage to the population of B. lycium Royle. Because of lack of awareness, people use this plant for stall feeding their animals and fire fuel, so in recent years, it has been vanished from a big area. It is the need of the hour to take the immediate attention to conserve this species.

The TPC was high in leaf samples collected from Chanjhal, Muzaffarabad District of AJ\&K. The highest total chlorophyll contents were found in samples collected from Sathrian, Neelum District. The highest antioxidant activity with the lowest IC50 values was obtained from the root sample collected from Bakreyali, Muzaffarabad District, as compared with other districts. The concentration of berberine was found to be 4.76 percent in the root bark (sample collected from Muzaffarabad District) of B. lycium Royle, estimated by high-performance liquid chromatography (HPLC). In syrup composition, $0.95 \mathrm{mg} / 5 \mathrm{ml}$ of berberine was used. B. lycium Royle possesses powerful antioxidant activity in its all parts, especially root, stem, and fruit. Fruits are already used as food in hilly areas of AJ\&K. Another important finding from the present study is that change in the environment has a big impact on the chemical composition of the same species, so its medicinal properties get changed. Hence, it is concluded that amongst the five districts, the plant parts (stem, fruits, and root) collected from Muzaffarabad District, AJ\&K, showed the highest medicinal potential due to its unique climatic conditions.

\section{Data Availability}

The data used to support the findings of this study are included within the article.

\section{Conflicts of Interest}

The authors declare that they have no conflicts of interest.

\section{Acknowledgments}

The authors thank local community for their interviews regarding data collection for the current study. The authors also thank Dr. Tariq Habib, Department of Botany, University of Azad Jammu and Kashmir, Pakistan, for the identification of collected plant species. We acknowledge Taif University Researchers Supporting Project Number (TURSP-2020/68), Taif University, Taif, Saudi Arabia.

\section{References}

[1] H. Khan, J. Khan, U. A. Khan et al., "Phytochemical assessment and evaluation of antibacterial potential of selected ethno medicinal plant against skin pathogens from the waraffected region of north-west Pakistan," Journal of Entomology and Zoology Studies, vol. 5, no. 1, p. 18, 2017.

[2] M. I. Ch, M. Khan, and A. Ullah Shah, "An ethnomedicinal inventory of plants used for family planning and sex diseases treatment in Samahni valley, (AK) Pakistan," Pakistan Journal of Biological Sciences: PJBS, vol. 9, pp. 2546-2555, 2006.

[3] M. Hamayun, "Ethnobotanical studies of some useful shrubs and trees of district buner, NWFP, Pakistan," Ethnobotanical Leaflets, vol. 2003, no. 1, p. 12, 2003.

[4] Z. Shinwari, S. Gilani, M. Kohjoma, and T. Nakaike, "Status of medicinal plants in Pakistani hindukush Himalayas," in Proceedings of Nepal-Japan Joint Symposium on Conservation and Utilization of Himalayan Med Resour, pp. 257-264, Kathmandu, Nepal, November 2000.

[5] M. Ishtiaq, W. Hanif, M. A. Khan, M. Ashraf, and A. M. Butt, "An ethnomedicinal survey and documentation of important medicinal folklore food phytonims of flora of samahni valley, (azad kashmir) Pakistan," Pakistan Journal of Biological Sciences, vol. 10, no. 13, pp. 2241-2256, 2007.

[6] F. Ishtiaq, S. M. Clegg, A. B. Phillimore, R. A. Black, I. P. F. Owens, and B. C. Sheldon, "Biogeographical patterns of blood parasite lineage diversity in avian hosts from southern Melanesian Islands," Journal of Biogeography, vol. 37, no. 1, pp. 120-132, 2009.

[7] H. Ali, S. Uddin, and S. Jalal, "Chemistry and biological activities of Berberis lycium royle," Journal of Biologically Active Products from Nature, vol. 5, no. 5, pp. 295-312, 2015.

[8] H. Sevik, D. Guney, H. Karakas, and G. Aktar, "Change to amount of chlorophyll on leaves depend on insolation in some landscape plants," International Journal of Environmental Sciences, vol. 3, no. 3, pp. 1057-1064, 2012.

[9] H. Wang, C. Zhu, Y. Ying, L. Luo, D. Huang, and Z. Luo, "Metformin and berberine, two versatile drugs in treatment of common metabolic diseases," Oncotarget, vol. 9, no. 11, pp. 10135-10146, 2018. 
[10] M. Adhikari, R. Thapa, R. M. Kunwar, H. P. Devkota, and P. Poudel, "Ethnomedicinal uses of plant resources in the machhapuchchhre rural municipality of Kaski district, Nepal," Medicines, vol. 6, no. 2, p. 69, 2019.

[11] T. Hatano, H. Kagawa, T. Yasuhara, and T. Okuda, "Two new flavonoids and other constituents in licorice root: their relative astringency and radical scavenging effects," Chemical and Pharmaceutical Bulletin, vol. 36, no. 6, pp. 2090-2097, 1998.

[12] S. K. Srivastava, A. K. S. Rawat, and S. Mehrotra, "Pharmacognostic evaluation of the roots of Berberis lycium royle," Oriental Pharmacy and Experimental Medicine, vol. 10, no. 3, pp. 184-190, 2010.

[13] I. Khan, H. Ahmad, B. Ahmad, and S. Azam, "Antiglycation and antioxidation properties of Berberis lyceum and Terminalia chebula: possible role in curing diabetes and slowing aging," Pakistan Journal of Botany, vol. 46, no. 4, pp. 14691471, 2014.

[14] S. Garhwal, "Analysis of berberine content using HPTLC fingerprinting of root and bark of three Himalayan berberis species," Asian Journal of Biotechnology, vol. 2, pp. 239-245, 2010.

[15] M. Gulfraz, M. Arshad, N. Nayyer, N. Kanwal, and U. Nisar, "Investigation for bioactive compounds of Berberis lyceum royle and Justicia adhatoda L.," Ethnobotanical Leaflets, vol. 2004, no. 1, p. 5, 2004.

[16] V. Chander, J. Aswal, R. Dobhal, and D. Uniyal, "A review on pharmacological potential of berberine; an active component of Himalayan Berberis aristata," The Journal of Phytopharmacology, vol. 6, no. 1, pp. 53-58, 2017.

[17] A. Ahmad, S. Mehmood, and M. Gulfraz, "Bone healing properties of Berberis lycium (royal): a case study," Case Study and Case Report, vol. 1, no. 1, pp. 1-5, 2011.

[18] H. Shah, A. A. Shad, S. Perveen, S. Khattak, and K. Fatima Kha, "Physiochemical composition of wild medicinal plant Berberis lycium," Journal of Applied Sciences, vol. 3, no. 6, pp. 370-375, 2003.

[19] S. Zain-ul-Abidin, R. Khan, M. Ahmad et al., "Ethnobotanical survey of highly effective medicinal plants and phytotherapies to treat diabetes mellitus II in south-west Pakistan," Indian Journal of Traditional Knowledge, vol. 17, no. 4, pp. 682-690, 2018.

[20] Z.-U.-R. Mashwani, M. A. Khan, S. Irum, and M. Ahmad, "Antioxidant potential of root bark of Berberis lycium royle. from Galliyat, western Himalaya, Pakistan," Pakistan Journal of Botany, vol. 45, pp. 231-234, 2013.

[21] N. Akhtar, B. Ihsan-ul-Haq, and B. Mirza, "Phytochemical analysis and comprehensive evaluation of antimicrobial and antioxidant properties of 61 medicinal plant species," Arabian journal of chemistry, vol. 11, no. 8, pp. 1223-1235, 2018.

[22] M. Gulfraz, G. Qadir, F. Nosheen, and Z. Parveen, "Antihyperglycemic effects of Berberis lyceum royle in alloxan induced diabetic rats," Diabetologia Croatica, vol. 36, no. 3, pp. 49-54, 2007.

[23] P. Sood, R. Modgil, and M. Sood, "Berberis lycium a medicinal plant with immense value," Indian Journal of Pharmaceutical and Biological Research, vol. 1, no. 1, pp. 27-37, 2013.

[24] R. R. Stewart, "History and exploration of plants in Pakistan and adjoining areas," 1982.

[25] R. A. Qureshi, M. A. Ghufran, S. A. Gilani, K. Sultana, and M. Ashraf, "Ethnobotanical studies of selected medicinal plants of Sudhan gali and Ganga Chotti hills, district Bagh, Azad Kashmir," Pakistan Journal of Botany, vol. 39, no. 7, pp. 2275-2283, 2007.
[26] M. A. Shah, S. K. Sherwani, M. Sualeh, S. Kanwal, H. N. Khan, and S. U. Kazmi, "In vitro anthelmintic and antiurolithic assessment of Berberis lycium root bark," Journal of Pharmacognosy and Phytochemistry, vol. 3, no. 2, 2014.

[27] A. Mhamdi and F. Van Breusegem, "Reactive oxygen species in plant development," Development, vol. 145, no. 15, Article ID dev164376, 2018.

[28] N. Wang, L. Zhu, X. Zhao, W. Yang, and H. Sun, "Improved HPLC method for the determination of moxifloxacin in application to a pharmacokinetics study in patients with infectious diseases," International Scholarly Research Notices, vol. 2013, Article ID 462918, 7 pages, 2013.

[29] G. J. Martin, Ethnobotany: A Methods Manual, Routledge, Oxfordshire, UK, 2010.

[30] Y. Aumeeruddy, "People and plants Himalayas," Country and Site Planning Report for Pakistan, p. 17, European Union, Maastricht, Netherlands, 2021.

[31] F. Hussain, A. Khaliq, and M. Durrani, "Ethnobotanical studies on some plants of Dabargai hills Swat," in Proceedings of First Training Workshop on Ethnobotany and its Application to Conservation, pp. 207-215, Islamabad, Pakistan, September 1996.

[32] P. A. Delcourt, H. R. Delcourt, P. A. Cridlebaugh, and J. Chapman, "Holocene ethnobotanical and paleoecological record of human impact on vegetation in the little Tennessee river valley, Tennessee," Quaternary Research, vol. 25, no. 3, pp. 330-349, 1896.

[33] L. L. Borges, S. F. Alves, B. L. Sampaio, E. C. Conceição, M. T. F. Bara, and J. R. Paula, "Environmental factors affecting the concentration of phenolic compounds in myrcia tomentosa leaves," Revista Brasileira de Farmacognosia, vol. 23, no. 2, pp. 230-238, 2013.

[34] M. Ibrar, F. Hussain, and A. Sultan, "Ethnobotanical studies on plant resources of Ranyal hills, District Shangla, Pakistan," Pakistan Journal of Botany, vol. 39, no. 2, p. 329, 2007.

[35] V. Krishnan, S. Ahmad, and M. Mahmood, "Antioxidant potential in different parts and callus of gynura procumbens and different parts of gynura bicolor," BioMed Research International, vol. 2015, Article ID 147909, 7 pages, 2015.

[36] S. Sabir, K. Tahir, N. Rashid, S. Naz, B. Masood, and M. A. Shah, "Phytochemical and antioxidant studies of Berberis lycium," Pakistan Journal of Pharmaceutical Sciences, vol. 26, no. 6, pp. 1165-1172, 2013.

[37] H. Nasri, A. Baradaran, H. Shirzad, and M. Rafieian-Kopaei, "New concepts in nutraceuticals as alternative for pharmaceuticals," International Journal of Preventive Medicine, vol. 5, no. 12, pp. 1487-99, 2014. 